Bossen, D., Veenhof, C., Dekker, J., Bakker, D.H. de. The effectiveness of self-guided web-basech physical activity interventions among patients with a chronic disease: a systematic review.

\begin{tabular}{|l|l|}
\hline $\begin{array}{l}\text { Postprint } \\
\text { Version }\end{array}$ & 1.0 \\
\hline Journal website & http://dx.doi.org/10.1123/ipah.2012-0152 \\
\hline Pubmed link & $\underline{\text { http://www.ncbi.nlm.nih.gov/pubmed/23493018 }}$ \\
\hline DOI & $10.1123 /$ jpah.2012-0152 \\
\hline
\end{tabular}

This is a NIVEL certified Post Print, more info at http://www.nivel.eu

\title{
The Effectiveness of Self-Guided Web-Based Physical Activity Interventions Among Patients With a Chronic Disease: A Systematic Review
}

\author{
DANiËL Bossen, Cindy VeEnHOF, JoOst DEKKER, AND DinNY DE BAKKER
}

\begin{abstract}
Background: Despite well-documented health benefits, adults with a physical chronic condition do not meet the recommended physical activity (PA) guidelines. Therefore, secondary prevention programs focusing on PA are needed. Web-based interventions have shown promise in the promotion of PA behavior change. We conducted a systematic review to summarize the evidence about the effectiveness of web-based PA interventions in adults with chronic disease. Methods: Articles were included if they evaluated a web-based PA intervention and used a randomized design. Moreover, studies were eligible for inclusion if they used a non- or minimal-treatment control group and if PA outcomes measures were applied. Seven articles were included. Results: Three highquality studies were statistically significant to the control group, whereas 2 high- and 2 low-quality studies reported nonsignificant findings. Conclusion: Our best evidence synthesis revealed that there is conflicting evidence on the effectiveness of web-based PA interventions in patients with a chronic disease.
\end{abstract}

Chronic diseases, such as osteoarthritis, type 2 diabetes, and coronary heart disease, are a major cause of disability worldwide. A chronic disease negatively affects quality of life due to physical and psychological consequences. ${ }^{1}$ With an aging population in the western world, it is expected that the number of patients with a chronic disease will increase substantially. ${ }^{2}$ Strong evidence indicates that physical activity (PA) has important health benefits for patients with a chronic disease, including reduced pain, improved function, and a reduced risk of disability. ${ }^{3-5}$ Moreover, PA has also been associated with psychological benefits and improvements in quality of life. ${ }^{6,7}$ In general, PA is defined as any bodily movement produced by contraction of skeletal muscles that results in an expenditure of energy. ${ }^{8}$ Regular PA is essential for healthy people and people with a chronic disease. Nevertheless, current estimates indicate that two-thirds of the adult population in the European Union do not meet the recommended levels of PA. ${ }^{9}$ Substantial evidence has confirmed that this percentage is even higher among patients with a chronic 
Bossen, D., Veenhof, C., Dekker, J., Bakker, D.H. de. The effectiveness of self-guided web-basech physical activity interventions among patients with a chronic disease: a systematic review.

disease. ${ }^{10}$ Therefore, PA has a public health priority and is considered as an essential component in the management of several chronic disorders.

To enhance PA and maintain higher levels of PA in patients with a chronic disease, a variety of methods has been developed. Traditionally, PA behavior change interventions use face-to-face delivery or printed materials.

Findings from a meta-analysis showed that these interventions are effective in the promotion of PA among chronically ill. ${ }^{5}$ In particular, interventions based on a behavioral strategy (eg, consequences, feedback, goal setting, self-monitoring) are more effective than interventions that do not include a behavioral component. Due to the increasing number of internet users, ${ }^{11}$ researchers and health providers focused on internet technology to induce health behavior change. ${ }^{12,13}$ The internet has created opportunities to distribute cost-effective behavior interventions, ${ }^{14}$ which are available 24 hours per day and widely accessible. Moreover, the internet is convenient, anonymous, and appealing to those who want to work in their own environment and in their own time. ${ }^{15}$ However, aforementioned advantages may also be viewed as limitations.

Although open access is one of the primary advantages of the internet, it may also be a disadvantage for those who lack the skills to use the World Wide Web.

Furthermore, absence of face-to-face interaction and lack of social control may reduce trust and intimacy and may lead to miscommunication and poor retention rates. ${ }^{16}$ Although the number of internet users is increasing, we should not be blind to the fact that most of the world's population (70\%) does not have access to the internet. ${ }^{17}$ In particular, elderly, unemployed, less educated, ${ }^{18,19}$ and those with a low e-Health literacy ${ }^{20}$ have less access to computers and are less likely to use interventions through the internet.

Internet-based therapies differ in content and purpose.

Barak et al identified 4 different internet-supported interventions based on their mode of delivery: ${ }^{16}$ (1) webbased interventions, (2) online counseling and therapy, (3) internet-operated therapeutic software, and (4) other online activities (blogs, online support groups). Webbased interventions and online counseling are mostly used in behavior-change education. ${ }^{21}$ Web-based interventions are primarily self-guided, while online counseling interventions require extensively trained therapists for personal guidance. While online counseling provides individualized guidance, webbased interventions have the potential power to reach a large population at low cost. $^{16}$ This unique advantage has led to the growth of numerous web-based PA interventions in recent years.

Previous research has identified that web-based interventions are successful in improving PA behavior in healthy adults. ${ }^{22-27}$ These reviews revealed that, in general, web-based courses were superior to waiting list controls and equivalent to conventional interventions, even though effect sizes were small. Although considerable research has been devoted to healthy populations, rather less attention has been paid to PA website interventions among patients with a chronic disease. In comparison with healthy people, patients with a chronic disease have different motivations, abilities, and barriers with regard to PA. ${ }^{28}$ People with a chronic disease perceive unique barriers, such as pain, fatigue and reduced physical performance capacity. These barriers vary among different patient populations. ${ }^{29,30}$ Therefore, people suffering from a chronic disorder may have other perspectives, needs, and desires with respect to PA promotion than healthy persons. ${ }^{31,32}$ As a consequence, 
Bossen, D., Veenhof, C., Dekker, J., Bakker, D.H. de. The effectiveness of self-guided web-basech physical activity interventions among patients with a chronic disease: a systematic review. Journal of Physical Activity \& Health: 2014, 11(3), 665-677

interventions focusing on healthy adults and the chronically ill differ in content. Because PA interventions for healthy adults focus on general PA determinants (eg, health behaviors, time barriers, and social support), ${ }^{33}$ interventions for individuals with a chronic disease predominantly address specific PA barriers ${ }^{34}$ (eg, pain, fear of hypogelmica, anxiety). To date, no reviews of PA web-based interventions among patients with a chronic disease have been performed. Therefore, the aim of this review is to summarize the effectiveness of webbased PA interventions in patients with a chronic disease.

\section{METHODS}

\section{Search Strategy}

A computerized literature search was performed using PubMed (1966 to April 2011), CINAHL (1982 to April 2011), Embase (1980 to April 2011) and Cochrane Controlled Trial Register (February 2011). The principal researcher (DB) carried out an initial database search to identify relevant articles. The search strategy consisted of combinations of free text and medical subject heading terms related to PA, the internet, chronic disease, and intervention study. Keywords and medical subject heading terms used in the search were (1) physical activity or physical fitness or motor activity or exercise or physical education or behavior change; (2) AND internet or website or World Wide Web or web-based or internet-based; (3) AND chronic disease or chronic illness or chronic condition; (4) AND intervention or study or randomized controlled trial or clinical controlled trial. The search strategy was formulated in PubMed and adapted for use in other databases. In addition, we hand-searched the reference lists of included studies and other systematic reviews ${ }^{5,16,22-26,35-38}$ for potential relevant articles.

\section{Inclusion and Exclusion Criteria}

Types of Studies. Included studies were randomized controlled trials or controlled clinical trials published in the English or Dutch languages.

Types of Participants. Participants older than 18 years with a chronic disease according to the International Classification of Diseases (ICD-10) were included. A chronic disease is defined as a "disease of long duration and generally slow progression." Common chronic disorders include diabetes mellitus, ischemic heart disease, chronic obstructive pulmonary disease, and arthritis. According to current guidelines, obesity (BMI greater than or equal to $30 \mathrm{~kg} / \mathrm{m} 2$ ) was considered a chronic disease. ${ }^{39}$ Studies focusing on chronic mental illnesses were excluded. Types of Interventions. In this study, we used the classification of Barak et $\mathrm{al}^{16}$ for the selection of webbased interventions. Eligible web-based interventions were classified as self-guided programs operated through a website to realize PA behavior change. In addition, studies focusing on other behavioral change components (eg, weight reduction or dietary habits) other than PA were also included. Self-guided interventions incorporate minimal human support. Generally, this means that the content is presented in a highly structured format with automatic functions (eg, automatic text messages, automatic e-mail, and noninteractive video) without human support. Studies were excluded if interventions comprised direct human contact (eg, through online counseling, chat, or interactive video communication). 
Bossen, D., Veenhof, C., Dekker, J., Bakker, D.H. de. The effectiveness of self-guided web-basech physical activity interventions among patients with a chronic disease: a systematic review.

Although studies with additional treatments arms were included (eg, face-to-face sessions), only the effects of minimum human interventions were analyzed. Types of Control Interventions. Only studies in which web-based PA programs were compared with no or minimal treatments were included.

Types of Outcome Measures. Only studies with the outcome measure PA were included. There are several subjective (eg, questionnaires, PA diary) and objective (eg, accelerometer, pedometer) methods in measuring PA. All PA measures, either objective or subjective, were included.

\section{Procedure of Inclusion}

The procedure of inclusion of studies was based on the recommendations as described by Tulder et al. ${ }^{40}$ This procedure consisted of 2 stages. First, titles and abstracts were screened independently by 2 reviewers (DB and CV). Studies were excluded if the title and/or abstract did not meet the inclusion criteria. Second, fulltext articles were reviewed by the same 2 reviewers, and studies were excluded if the content did not meet the inclusion criteria.

Subsequently, disagreements regarding article inclusion were resolved with discussion and consensus between the 2 reviewers.

\section{Assessment of Methodological Quality}

The methodological quality of all articles was independently assessed by 2 reviewers (DB and CV) using a criteria list, ${ }^{40}$ as recommended by the Cochrane collaboration back review group (Table 1). Several systematic reviews in the area of PA and exercise therapy have used this list. ${ }^{22,41}$ The list of Van Tulder et $\mathrm{al}^{40}$ contains an 11point scoring system related to selection bias (3 criteria), performance bias ( 4 criteria), attrition bias (2 criteria), and detection bias (2 criteria). One performance bias criterion, "care provider blinded," was not considered appropriate for webbased interventions and was omitted from the criteria list.

All items from the list (10 items) were scored as "yes” (1 point), “no” (0 points), or "unclear" (0 points). Studies with a score of $\geq 6$ out of 10 were judged to be of high quality.

Disagreements about the methodological quality between the 2 reviewers were resolved by discussion and consensus.

\section{Data Analysis}

Data were extracted by using a predefined data extraction form, with study characteristics (type of study, year of publication), patient's characteristics (number, age, gender, and chronic disease), intervention characteristics (duration, theoretical foundations, description of contents) and pre- and posttest PA outcomes. Wherever possible, we calculated effect sizes for papers in which no effect size was reported. Furthermore, according to Hoehner et al, ${ }^{58}$ the net effect for all PA measurements was calculated as relative percent change from baseline. Clinical heterogeneity was assessed by inspecting the type of participants, interventions and outcomes of each study. Owing to the considerable variety of PA measurements, type of PA outcomes, follow-up periods, and intervention duration, results could not be reliably combined.

Therefore, we decided to perform a qualitative systematic review instead of a metaanalysis. A best evidence synthesis was performed based on 5 levels of evidence ${ }^{40}$ (see Table 2). In this strategy, conclusions are based on consistency of results and the 
Bossen, D., Veenhof, C., Dekker, J., Bakker, D.H. de. The effectiveness of self-guided web-basech physical activity interventions among patients with a chronic disease: a systematic review.

methodological quality of the original studies. Strong (multiple high-quality trials), moderate (low-quality trials and/or one high-quality trial)

\section{[TABLE 1$]$}

and limited (at least one low-quality trial) evidence is detected if more than $75 \%$ of the studies find results in the same direction. Findings are considered conflicting if studies report inconsistent results, and no evidence is defined if there are no randomized trials available.

\section{RESULTS}

\section{Selection of Studies}

The flowchart in Figure 1 gives an overview of the selection procedure. The database (438) and hand search (24) yielded 462 citations. Subsequently, 455 publications were eliminated based on title, abstract, and full text.

Ultimately, 7 articles fulfilled the inclusion criteria and were included in this review.

\section{[TABLE 2] [FIGURE 1]}

\section{Methodological Quality}

Initially, there was disagreement between the reviewers about methodological quality scores in 12 of the $70(7 \times 10)$ items. After using the consensus method, no disagreement persisted. Table 3 presents the methodological quality of the included studies. Of the 7 studies selected for inclusion, 5 studies were graded as high methodological quality, ${ }^{4-46}$ and 2 were graded as low quality. ${ }^{47,48}$ Considering that concealment in web-based intervention studies is inappropriate, none of the studies met the "blinding of patients" criteria. Several studies revealed incomplete information about "adequate randomization," $42,46,47$ "concealment of treatment allocation,"42-44,47,48 "blinding of outcome assessment,"43-45,47 and "cointerventions avoided or similar. ,43-45,47

\section{Characteristics of Selected Studies}

Study characteristics are presented in Table 4 . All studies were published between 2001 and 2010. Of the 7 selected studies, 6 were performed in the United States ${ }^{42-47}$ and 1 in the United Kingdom. ${ }^{48}$ Five studies were randomized controlled trials, ${ }^{42,43,45,46,48}$ and 2 studies were randomized controlled pilot studies. ${ }^{44,47}$ Five studies had a 2-arm design, ${ }^{42,44-46,48}$ while 2 studies had a 3-arm design ${ }^{43,47}$ in which 2 groups received a different treatment. Regarding the 3-arm studies, distinction between the 2 investigated interventions was the amount of personalized contact between participant and a healthcare provider. A significant number of studies defined eligibility criteria regarding age, baseline PA level, type of disease, and contraindications for PA. Table 5 gives an overview of the selected outcome measures.

In all studies, PA behavior was reported as an outcome measure. Although 1 study applied a combination of subjective and objective measurements, ${ }^{42}$ the majority of studies used self-reported PA questionnaires only. ${ }^{43-48}$ Included interventions used a variety of PA outcome measures, such as moderate PA, walking, leisure time PA, 
Bossen, D., Veenhof, C., Dekker, J., Bakker, D.H. de. The effectiveness of self-guided web-basech physical activity interventions among patients with a chronic disease: a systematic review.

and PA caloric expenditure. With regard to all included studies, interventions were compared with no (waiting list controls) or minimal (attention controls) treatment.

\section{Characteristics of Study Populations}

Table 4 shows that the number of participants across the studies ranged from 22-463. The majority of participants were female; the percentage of male participants varied between $10 \%$ to $72.2 \%$. The mean age in the sample fluctuated between 38.7-76.2 years. The study population consisted of patients with various disorders, including multiple sclerosis, ${ }^{45}$ diabetes mellitus $2,{ }^{43,44}$ metabolic syndrome, ${ }^{42}$ physical disabilities, ${ }^{47}$ heart failure, ${ }^{46}$ and obesity. ${ }^{48}$ Four of the 7 studies were addressed to sedentary patients at baseline. ${ }^{43-45,47}$ The percentage of completes from enrolment to the final follow-up varied between $49.6 \%{ }^{47}$ and $89 \%$. ${ }^{45}$

\section{Characteristics of the Interventions}

Table 4 illustrates the characteristics of the web-based interventions. The results show that duration of the intervention varied from 1 month to 12 months. Four interventions intervened on PA only,42,44,45,47 and 3 interventions addressed additional health behavior components, $43,46,48$ such as dietary behavior and medication adherence. Included studies were either self-directed or had minimal contact with experts and/or health professionals. Three interventions used additional delivery components44,46,48 other than a website. These components contained automatic generated e-mails or noninteractive videos. Of the 7 described interventions, 5 were theory-driven.43-47 In 2 studies, interventions were developed according to the transtheoretical model.46,47 Other interventions were based on the social cognitive theory, the " 5 As" self-management model,43 and social ecological theory.43,44 Among the studies, the length of follow-up varied widely from 1 month47 to 12 months.48

\section{[ TABLE 3][TABLE 4][TABLE 5]}

\section{Effectiveness of Interventions}

Table 5 describes a variety of outcome measures and the results from the selected studies. PA pre- and posttest scores are presented for both intervention and control groups. A best-evidence synthesis was performed to summarize the effectiveness of web-based PA interventions.

Three high-quality studies showed significant improvements in PA in favor of the intervention group. ${ }^{43,45,46}$ Two high-quality trials reported nonsignificant differences in PA scores between intervention and control group, ${ }^{42,44}$ and 2 low-quality studies also reported nonsignificant differences between groups. ${ }^{47,48}$ Effect sizes ranged from $0.13^{42}-0.56{ }^{45}$ There is conflicting evidence whether webbased PA interventions are effective in patients with a chronic disease. As shown in Figure 2, the net effect sizes ranged from $-5 \%$ of minutes a day spent on walking to $185 \%$ of meeting $2-3$ days of exercise a week.

\section{DISCUSSION}

\section{Summary of Main Findings}

The current systematic review aimed to summarize the effectiveness of web-based PA interventions targeting patients with a chronic condition. The best-evidence 
Bossen, D., Veenhof, C., Dekker, J., Bakker, D.H. de. The effectiveness of self-guided web-basech physical activity interventions among patients with a chronic disease: a systematic review.

synthesis revealed conflicting results with regard to the effectiveness of web-based PA interventions in patients with a chronic disease. Although no conclusive evidence was found, a trend toward positive effects was identified in favor of the intervention groups. Three high-quality studies, ${ }^{43,45,46}$ reported significant effect sizes, and 2 high${ }^{42,44}$ and 2 low-quality studies ${ }^{47,48}$ did not reach statistical significance. Two studies ${ }^{45,47}$ reported medium effect sizes $(>0.3$ and $<0.5)$, while 3 other studies ${ }^{42-44}$ presented small effect sizes $(<0.2)$.

In the present review we found only 7 eligible studies which met our inclusion criteria. Along with the limited number of studies, sample sizes tended to be small, which reduced the statistical power in our review. Three out of 7 studies ${ }^{42,45,46}$ included fewer than 60 participants. Recognizing the lack of power, effect sizes were considered to gain insight into trends in the data. It is expected that with larger samples sizes, more between-group comparisons would be statically significant. Another factor that may have contributed to the conflicting evidence is the dropout rates in the individual studies. To illustrate, 2 large-sample-size studies with high drop-out rates ( $>50 \%$ ) reported nonsignificant findings, while 2 smaller studies with low drop-out rates $(<20 \%)$ yielded significant results. This review found, in line with others, ${ }^{25,49,50}$ substantial dropout rates (25.2\%).

\section{[FIGURE 2]}

Intervention groups suffered slightly more from dropout than the comparison group (27.2\% vs $24.1 \%$ ). Because the success of web-based interventions requires active participation, high dropout rates have been pointed out as a common concern in the field of web-based education. ${ }^{49,51} \mathrm{~A}$ factor that may have exacerbated dropout rates in our review is the patient characteristics, namely the sedentary participants diagnosed with a chronic disease. Research has indicated that a chronic condition and inactivity decrease the odds of using web-based interventions. ${ }^{32,52}$ Apparently, web-based interventions fail to reach those for whom PA behavior changes are most necessary. Another explanation for the high dropout may be that the intervention content was based on self-directed features with minimum personal contact. Research has suggested that therapeutic involvement may enhance participant engagement. ${ }^{51,53}$ Obviously, the low level of personal contact may have negatively impacted dropout rates because participants are less motivated and feel less obliged to continue. The use of certain "push factors," including automatic e-mails, periodic prompts, selfmonitoring, peer support, and provision of feedback may improve nonusage attrition. ${ }^{51}$ Further insights are needed to investigate which of those incentives keep participants engaged and which characteristics (eg, pain, fatigue, or reduced physical performance capacity) are related to dropout.

With regard to the methodological quality, 5 studies were rated as high quality, and 2 studies were classified as low quality. Six out of 7 articles were published after 2005. These numbers illustrate the increase use of webbased education in patients over recent years. Although interventions were mostly theory-driven to maintain increased levels of PA, the majority of studies failed to report long-term post-intervention follow-up. Only 1 study ${ }^{48}$ demonstrated interventions effects after 1 year. Therefore, future studies require a longer duration of follow-up ( $>1$ year). With respect to the measurements, most studies used self-reported questionnaires. This, however, is in contrast to prior recommendations because questionnaires may lead to recall error, perceived social desirability, and other biases. ${ }^{54}$ Subjective 
Bossen, D., Veenhof, C., Dekker, J., Bakker, D.H. de. The effectiveness of self-guided web-basech physical activity interventions among patients with a chronic disease: a systematic review.

measurements tend to overestimate true levels of PA, increase the variance in outcome measures, and subsequently lead to an attenuation of effectiveness. Despite limited evidence, observed results do not automatically imply clinical irrelevance. Contrarily, with respect to other behavior-change approaches, webbased behavior programs have the unique potential to reach large populations. Considering the size of the populations, even small effects may have large public health consequences. Research has shown that even small PA effects can lead to important health benefits.

Improvement in PA appears, particularly in older and atrisk populations, to be important to maintain functional independence. ${ }^{55}$ This provides support for more development and extensive implementation.

To our knowledge, this literature study differs from previous systematic reviews ${ }^{22-26}$ in the following ways.

Firstly, to enhance clinical validity, this review focused on self-help programs delivered through websites. Whereas previous reviews focused on internet interventions combined with therapeutic (online) counseling, we focused exclusively on self-help interventions with minimum therapeutic involvement. Secondly, included interventions were mainly developed to reinforce PA. Thirdly, to avoid heterogeneity of exposure among participants in the control group, content of the control groups concerned no or minimal treatment. Lastly, while other reviews included predominantly healthy persons, we focused solely on chronically ill patients.

\section{LIMITATIONS OF STUDY}

This review was limited by the small number of studies and heterogeneity in outcome measures and follow-up time. Therefore, we decided to conduct a bestevidence synthesis. A best-evidence synthesis is less sensitive than meta-analysis. Another limitation is that 3 included studies ${ }^{43,46,48}$ evaluated a multicomponent intervention (eg, a combination of physical activity and nutrition). Therefore, it is hard to determine with certainty whether the PA components were the actual determinants of the PA behavior change. Furthermore, we only considered English and Dutch studies and excluded dissertations and other gray literature. Therefore, it is possible that this review is not a complete representation of all available evidence.

\section{Implications for Future Research}

Although a trend toward positive effects was identified in favor of the intervention groups, our best evidence synthesis revealed that there is conflicting evidence on the effectiveness of web-based PA interventions in patients with a chronic disease. Studies in this review suffered from high drop-out and nonusage rates. Eysenbach calls this phenomenon "the law of attrition." 51 Therefore, it is advised that future interventions integrate more push factors (eg, automatic e-mails, weekly new content, short text messages) to improve study and program compliance. Website interventions to promote PA among the chronically ill are still in the preliminary stages of development.

There is a need for more published studies in this research area. Based upon this review, future research should (1) design more interventions specifically for patients with a chronic disease and low PA level, (2) explore which components reinforce adherence to web-based PA interventions, (3) use objective measures of PA, and (4) incorporate larger sample sizes to achieve sufficient statistical power. Moreover, 
Bossen, D., Veenhof, C., Dekker, J., Bakker, D.H. de. The effectiveness of self-guided web-basech physical activity interventions among patients with a chronic disease: a systematic review.

Journal of Physical Activity \& Health: 2014, 11(3), 665-677

future studies need to reach consensus on PA measures and should use a combination of validated questionnaires with objective measures to obtain the best results. Lastly, although not investigated in this review, issues related to access and disparities need to be better understood. Automated self-help intervention may contribute, in technical sense, to a reduction of health disparities worldwide. However, in practice, health education through the internet is predominantly used by well-educated and informed people who are already privileged in terms of health and healthcare utilization. ${ }^{55}$ Therefore, more research is needed to reach those who need the most care.

\section{REFERENCES}

1. Fried LP, Guralnik JM. Disability in older adults: evidence regarding significance, etiology, and risk. J Am Geriatr Soc. 1997;45(1):92-100.

2. World Health Organization. Preventing chronic diseases: a vital investment.

3. Warburton DE, Nicol CW, Bredin SS. Health benefits of physical activity: the evidence. CMAJ. 2006;174(6):801- 809.

4. Conn VS, Hafdahl AR, Brown LM. Meta-analysis of quality- of-life outcomes from physical activity interventions.

Nurs Res. 2009;58(3):175-183.

5. Conn VS, Hafdahl AR, Brown SA, Brown LM. Metaanalysis of patient education interventions to increase physical activity among chronically ill adults. Patient

Educ Couns. 2008;70(2):157-172.

6. Guszkowska M. Effects of exercise on anxiety, depression and mood [in Polish]. Psychiatr Pol. 2004;38(4):611-620.

7. Byrne A, Byrne DG. The effect of exercise on depression, anxiety and other mood states: a review.

J Psychosom Res. 1993;37(6):565-574.

8. Caspersen CJ, Powell KE, Christenson GM. Physical activity, exercise, and physical fitness: definitions and distinctions for health-related research. Public Health Rep. 1985;100(2):126-131.

9. Sjöström M, Oja P, Hagströmer M, Smith B, Bauman A. Health-enhancing physical activity across European Union countries: the Eurobarometer study. J Public Health (Bangkok). 2006;14:291-300.

10. Ashe MC, Miller WC, Eng JJ, Noreau L. Older adults, chronic disease and leisure-time physical activity. Gerontology. 2009;55(1):64-72.

11. Internet World Stats. Top 58 countries with highest Internet penetration rates.

12. Kummervold PE, Chronaki CE, Lausen B, et al. eHealth trends in Europe 2005-2007: a population-based survey. J

Med Internet Res. 2008;10(4):e42.

13. Ahern DK, Kreslake JM, Phalen JM. What is eHealth (6): perspectives on the evolution of eHealth research. J Med

Internet Res. 2006;8(1):e4.

14. Brug J, Oenema A, Kroeze W, Raat $\mathrm{H}$. The Internet and nutrition education: challenges and opportunities. Eur

J Clin Nutr. 2005;59(Suppl 1):S130-S137.

15. Ritterband LM, Gonderfrederick LA, Cox DJ, et al.

Internet interventions: in review, in use, and into the future. Prof Psychol Res Pr. 2003;34(5):527-534.

16. Barak A, Klein B, Proudfoot JG. Defining Internet-supported therapeutic interventions. Ann Behav Med. 2009;38(1):4- 17.

17. Internet World Stats. World Internet Users and Population Stats. Internet World Stats . Accessed February 2, 2012. 
Bossen, D., Veenhof, C., Dekker, J., Bakker, D.H. de. The effectiveness of self-guided web-basech physical activity interventions among patients with a chronic disease: a systematic review.

Journal of Physical Activity \& Health: 2014, 11(3), 665-677

18. Paul CL, Carey ML, Hall AE, et al. Improving access to information and support for patients with less common cancers: hematologic cancer patients' views about Webbased approaches. J Med Internet Res. 2011;13(4):e112.

19. Renahy E, Parizot I, Chauvin P. Health information seeking on the Internet: a double divide? Results from a representative survey in the Paris metropolitan area, France, 20052006. BMC Public Health. 2008;8:69.

20. Neter E, Brainin E. eHealth literacy: extending the digital divide to the realm of health information. J Med Internet

Res. 2012;14(1):e19.

21. Barak A, Hen L, Nissim MB, Shapira N. A comprehensive review and a meta-analysis of the effectiveness of Internet-based psychotherapeutic interventions.

J Technol Hum Serv. 2008;26(2-4):109-159.

22. van den Berg MH, Schoones JW, Vliet Vlieland TP.

Internet-based physical activity interventions: a systematic review of the literature. J Med Internet Res. 2007;9(3):e26.

23. Vandelanotte C, Spathonis KM, Eakin EG, Owen N.

Website-delivered physical activity interventions a review of the literature. Am J Prev Med. 2007;33(1):54-64.

24. Hamel LM, Robbins LB, Wilbur J. Computer- and Web-based interventions to increase preadolescent and adolescent physical activity: a systematic review. J Adv Nurs. 2011;67(2):251-268.

25. Norman GJ, Zabinski MF, Adams MA, et al. A review of eHealth interventions for physical activity and dietary behavior change. Am J Prev Med. 2007;33(4):336-345.

26. Neville LM, O'Hara B, Milat A. Computer-tailored physical activity behavior change interventions targeting adults: a systematic review. Int J Behav Nutr Phys Act. 2009;6:30.

27. Pratt M, Sarmiento OL, Montes F, et al. The implications of megatrends in information and communication technology and transportation for changes in global physical activity. Lancet. 2012;380:282-293.

28. Schutzer KA, Graves BS. Barriers and motivations to exercise in older adults. Prev Med. 2004;39(5):1056-1061.

29. Shih M, Hootman JM, Kruger J, Helmick CG. Physical activity in men and women with arthritis National Health Interview Survey, 2002. Am J Prev Med. 2006;30(5):385- 393.

30. Der Ananian C, Wilcox S, Saunders R, Watkins K, Evans A. Factors that influence exercise among adults Effectiveness of Web-Based PA Interventions with arthritis in three activity levels. Prev Chronic Dis. 2006;3(3):A81.

31. Crombie IK, Irvine L, Williams B, et al. Why older people do not participate in leisure time physical activity: a survey of activity levels, beliefs and deterrents. Age Ageing.

2004;33(3):287-292.

32. Kelders SM, Gemert-Pijnen JE, Werkman A, Nijland N, Seydel ER. Effectiveness of a Web-based intervention aimed at healthy dietary and physical activity behavior: a randomized controlled trial about users and usage. J Med Internet Res. 2011;13(2):e32.

33. Sherwood NE, Jeffery RW. The behavioral determinants of exercise: implications for physical activity interventions.

Annu Rev Nutr. 2000;20:21-44.

34. Richardson CR, Mehari KS, McIntyre LG, et al. A randomized trial comparing structured and lifestyle goals in an Internet-mediated walking program for people with type 2 diabetes. Int J Behav Nutr Phys Act. 2007;4:59.

35. Aalbers T, Baars MA, Rikkert MG. Characteristics of effective Internet-mediated interventions to change lifestyle in people aged 50 and older: a systematic review. Ageing Res Rev. 2011;10(4):487-497.

36. Marcus BH, Ciccolo JT, Sciamanna CN. Using electronic/ computer interventions to promote physical activity. Br J Sports Med. 2009;43(2):102-105.

37. Webb TL, Joseph J, Yardley L, Michie S. Using the Internet to promote health behavior change: a systematic review and meta-analysis of the impact of theoretical basis, use of behavior change techniques, and mode of delivery on efficacy. J Med Internet Res. 2010;12(1):e4. 
Bossen, D., Veenhof, C., Dekker, J., Bakker, D.H. de. The effectiveness of self-guided web-basech physical activity interventions among patients with a chronic disease: a systematic review.

Journal of Physical Activity \& Health: 2014, 11(3), 665-677

38. Murray E, Burns J, See TS, Lai R, Nazareth I. Interactive health communication applications for people with chronic disease. Cochrane Database Syst Rev. 2005;

(4):CD004274.

39. Allison DB, Downey M, Atkinson RL, et al. Obesity as a disease: a white paper on evidence and arguments commissioned by the Council of the Obesity Society.

Obesity (Silver Spring). 2008;16(6):1161-1177.

40. van Tulder M, Furlan A, Bombardier C, Bouter L. Updated method guidelines for systematic reviews in the Cochrane collaboration back review group. Spine (Phila Pa 1976) 2003; 28(12):1290-1299.

41. Pisters MF, Veenhof C, van Meeteren NL, et al. Long-term effectiveness of exercise therapy in patients with osteoarthritis of the hip or knee: a systematic review. Arthritis Rheum. 2007;57(7):1245-1253.

42. Bosak KA, Yates B, Pozehl B. Effects of an Internet physical activity intervention in adults with metabolic syndrome. West J Nurs Res. 2010;32(1):5-22.

43. Glasgow RE, Kurz D, King D, et al. Outcomes of minimal and moderate support versions of an Internet-based diabetes self-management support program. J Gen Intern Med. 2010; 25(12):1315-1322.

44. McKay HG, King D, Eakin EG, Seeley JR, Glasgow RE. The diabetes network Internetbased physical activity intervention: a randomized pilot study. Diabetes Care. 2001;24(8):1328-1334.

45. Motl RW, Dlugonski D, Wojcicki TR, McAuley E, Mohr DC. Internet intervention for increasing physical activity in persons with multiple sclerosis. Mult Scler. 2011;17(1):116128. .

46. Tomita MR, Tsai BM, Fisher NM, et al. Effects of multidisciplinary Internet-based program on management of heart failure. J Multidiscip Healthc. 2008;2009(2):13-21.

47. Kosma M, Cardinal BJ, McCubbin JA. A pilot study of a Web-based physical activity motivational program for adults with physical disabilities. Disabil Rehabil. 2005;27(23):1435-1442.

48. McConnon A, Kirk SF, Cockroft JE, et al. The Internet for weight control in an obese sample: results of a randomised controlled trial. BMC Health Serv Res. 2007;7:206.

49. Wantland DJ, Portillo CJ, Holzemer WL, Slaughter R, McGhee EM. The effectiveness of Web-based vs. non- Web-based interventions: a meta-analysis of behavioral change outcomes. J Med Internet Res. 2004;6(4):e40.

50. Wangberg SC, Bergmo TS, Johnsen JA. Adherence in Internet-based interventions. Patient Prefer Adherence. 2008;2:57-65.

51. Eysenbach G. The law of attrition. J Med Internet Res. 2005;7(1):e11.

52. Steele RM, Mummery WK, Dwyer T. Examination of program exposure across intervention delivery modes: face-to-face versus Internet. Int J Behav Nutr Phys Act. 2007;4:7.

53. Brouwer W, Kroeze W, Crutzen R, et al. Which intervention characteristics are related to more exposure to Internetdelivered healthy lifestyle promotion interventions? A systematic review. J Med Internet Res. 2011;13(1):e2.

54. Sallis JF, Saelens BE. Assessment of physical activity by self-report: status, limitations, and future directions. Res Q Exerc Sport. 2000;71(2, Suppl):S1-S14

55. Gilmour JA. Reducing disparities in the access and use of Internet health information: a discussion paper. Int J Nurs Stud. 2007;44(7):1270-1278.

56. Goldstein MG, Whitlock EP, DePue J. Multiple behavioral risk factor interventions in primary care: summary of research evidence. Am J Prev Med. 2004;27(2, Suppl):61- 79.

57. Glanz K, Rimer BK, Viswanath K. Health behavior and health education: theory, research, and practice (4th edition). San Francisco: John Wiley \& Sons, Incorporated, 2008 B.C.: $465-486$.

58. Hoehner CM, Soares J, Parra Perez D, et al. Physical activity interventions in Latin America: a systematic review. Am J Prev Med. 2008;34(3):224-233. 
Bossen, D., Veenhof, C., Dekker, J., Bakker, D.H. de. The effectiveness of self-guided web-basech physical activity interventions among patients with a chronic disease: a systematic review.

Journal of Physical Activity \& Health: 2014, 11(3), 665-677

\section{TABLES AND FIGURES}

\section{Table 1 Criteria List for Assessment of Methodological Quality}

\begin{tabular}{l}
\hline Validity criteria \\
\hline A. Was the method of randomization adequate? \\
B. Was the treatment allocation concealed? \\
C. Were the groups similar at baseline regarding the most important prognostic indicators? \\
D. Was the patient blinded to the intervention? \\
E. Was the care provider blinded to the intervention?* \\
F. Was the outcome assessor blinded to the intervention? \\
G. Were co interventions avoided or similar? \\
H. Was the compliance acceptable in all groups? (<6 months studies $20 \%,>6$ months studies $30 \%)$ \\
I. Was the dropout rate described and acceptable? \\
J. Was the timing of the outcome assessment in all groups similar? \\
K. Did the analysis include an intention-to-treat analysis?
\end{tabular}

High quality; the study adequate fulfilled 6 or more out of 10 criteria.

Low quality; the study fulfilled less than 6 out of 10 criteria.

* Excluded in this review.

\section{Table 2 Best Evidence Synthesis}

\begin{tabular}{|c|c|}
\hline Level of evidence & Description \\
\hline Strong evidence & $\begin{array}{l}\text { Consistent findings in multiple } \\
\text { high-quality trials }\end{array}$ \\
\hline Moderate evidence & $\begin{array}{l}\text { Consistent findings in multiple } \\
\text { low-quality trials and/or one high- } \\
\text { quality trial }\end{array}$ \\
\hline Limited evidence & $\begin{array}{l}\text { Consistent findings in outcome } \\
\text { measures in at least one low- } \\
\text { quality trial }\end{array}$ \\
\hline Conflicting & $\begin{array}{l}\text { Inconsistent findings among mul- } \\
\text { tiple trials }\end{array}$ \\
\hline No evidence & No randomized trials available \\
\hline
\end{tabular}


Bossen, D., Veenhof, C., Dekker, J., Bakker, D.H. de. The effectiveness of self-guided web-basech physical activity interventions among patients with a chronic disease: a systematic review. Journal of Physical Activity \& Health: 2014, 11(3), 665-677

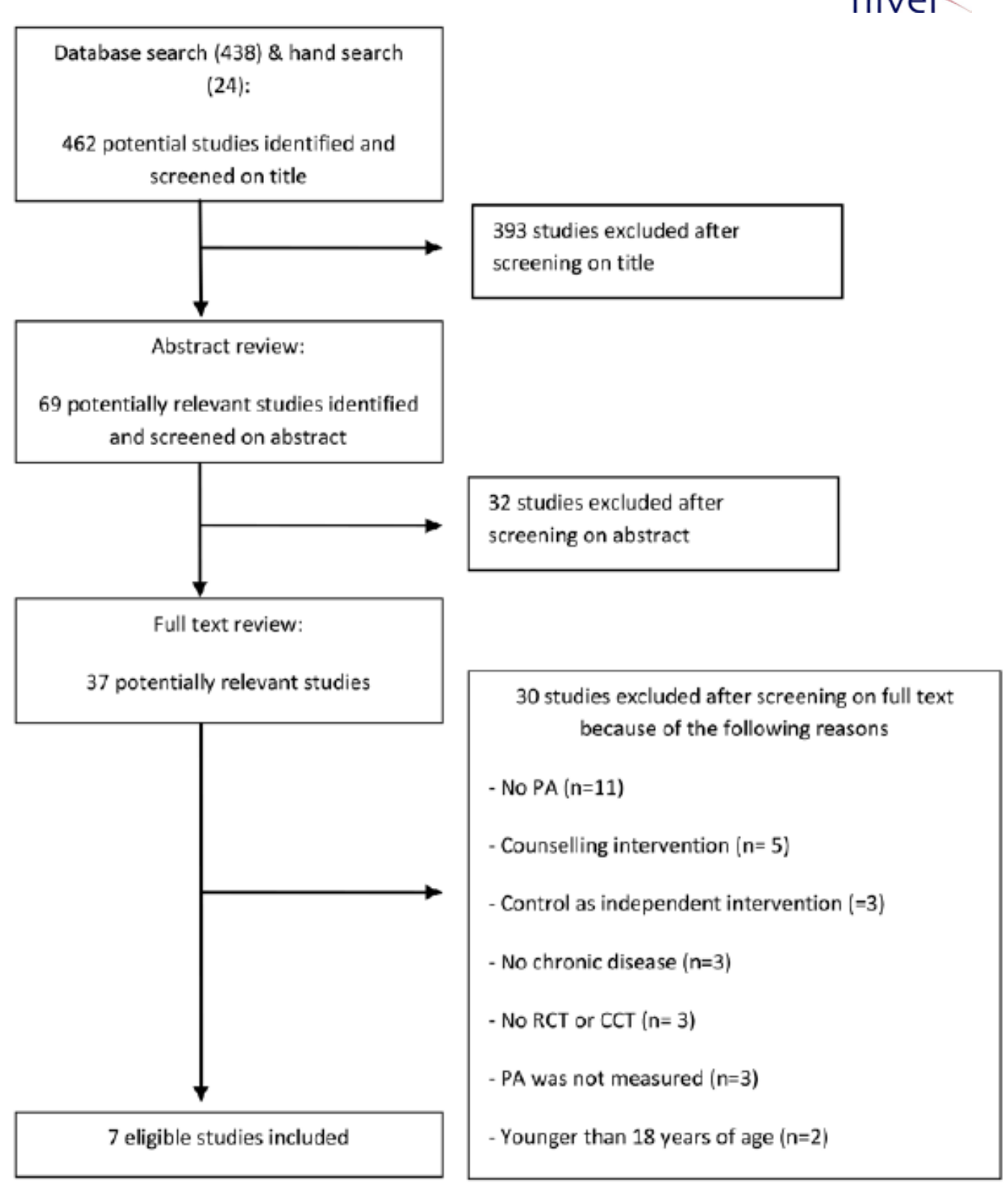

Figure 1 - Overview of the selection procedure. 
Bossen, D., Veenhof, C., Dekker, J., Bakker, D.H. de. The effectiveness of self-guided web-basech physical activity interventions among patients with a chronic disease: a systematic review.

Journal of Physical Activity \& Health: 2014, 11(3), 665-677

Table 3 Methodological Quality Assessment

\begin{tabular}{|c|c|c|c|c|c|c|c|c|}
\hline \multirow[b]{2}{*}{ Study } & \multicolumn{4}{|c|}{ Fulfilled validity criteria } & \multirow[b]{2}{*}{$\begin{array}{l}\text { Unfulfilled } \\
\text { validity } \\
\text { criteria }\end{array}$} & \multirow[b]{2}{*}{$\begin{array}{l}\text { Incomplete } \\
\text { information } \\
\text { for validity } \\
\text { assessment }\end{array}$} & \multirow[b]{2}{*}{$\begin{array}{l}\text { Internal } \\
\text { validity } \\
\text { score }\end{array}$} & \multirow[b]{2}{*}{$\begin{array}{l}\text { Methodological } \\
\text { quality }\end{array}$} \\
\hline & $\begin{array}{l}\text { Selection } \\
\text { bias } \\
(a, b, c)\end{array}$ & $\begin{array}{c}\text { Performance } \\
\text { bias } \\
\text { (d,g,h) }\end{array}$ & $\begin{array}{l}\text { Attrition } \\
\text { bias } \\
\text { (i and } k \text { ) }\end{array}$ & $\begin{array}{l}\text { Detection } \\
\text { bias } \\
\text { (f and j) }\end{array}$ & & & & \\
\hline Bosak, 2010 & $\mathrm{C}$ & $\mathrm{G}, \mathrm{H}$ & $\mathrm{I}, \mathrm{K}$ & $\mathrm{F}, \mathrm{J}$ & $\mathrm{D}$ & $\mathrm{A}, \mathrm{B}$ & 7 & High \\
\hline Glasgow, 2010 & $\mathrm{~A}, \mathrm{C}$ & $\mathrm{H}$ & $\mathrm{I}, \mathrm{K}$ & $\mathrm{J}$ & $\mathrm{D}$ & $\mathrm{B}, \mathrm{F}, \mathrm{G}$ & 6 & High \\
\hline Kosma, 2005 & $\mathrm{C}$ & - & - & $\mathrm{J}$ & $\mathrm{D}, \mathrm{H}, \mathrm{I}$ & A.B,F,G,K & 2 & Low \\
\hline McConnon, 2007 & $\mathrm{~A}, \mathrm{C}$ & G & $\mathrm{K}$ & $\mathrm{J}$ & $\mathrm{D}, \mathrm{F}, \mathrm{H}, \mathrm{I}$ & B & 5 & Low \\
\hline McKay, 2001 & $\mathrm{~A}, \mathrm{C}$ & $\mathrm{H}$ & $\mathrm{I}, \mathrm{K}$ & $\mathrm{J}$ & $\mathrm{D}$ & $\mathrm{B}, \mathrm{F}, \mathrm{G}$ & 6 & High \\
\hline Motl, 2010 & $\mathrm{~A}, \mathrm{~B}, \mathrm{C}$ & $\mathrm{H}$ & $\mathrm{I}, \mathrm{K}$ & $\mathrm{J}$ & $\mathrm{D}$ & $\mathrm{F}, \mathrm{G}$ & 7 & High \\
\hline Tomita, 2009 & $\mathrm{C}$ & $\mathrm{G}, \mathrm{H}$ & $\mathrm{I}, \mathrm{K}$ & $\mathrm{F}, \mathrm{J}$ & $\mathrm{D}$ & $\mathrm{A}, \mathrm{B}$ & 7 & High \\
\hline
\end{tabular}

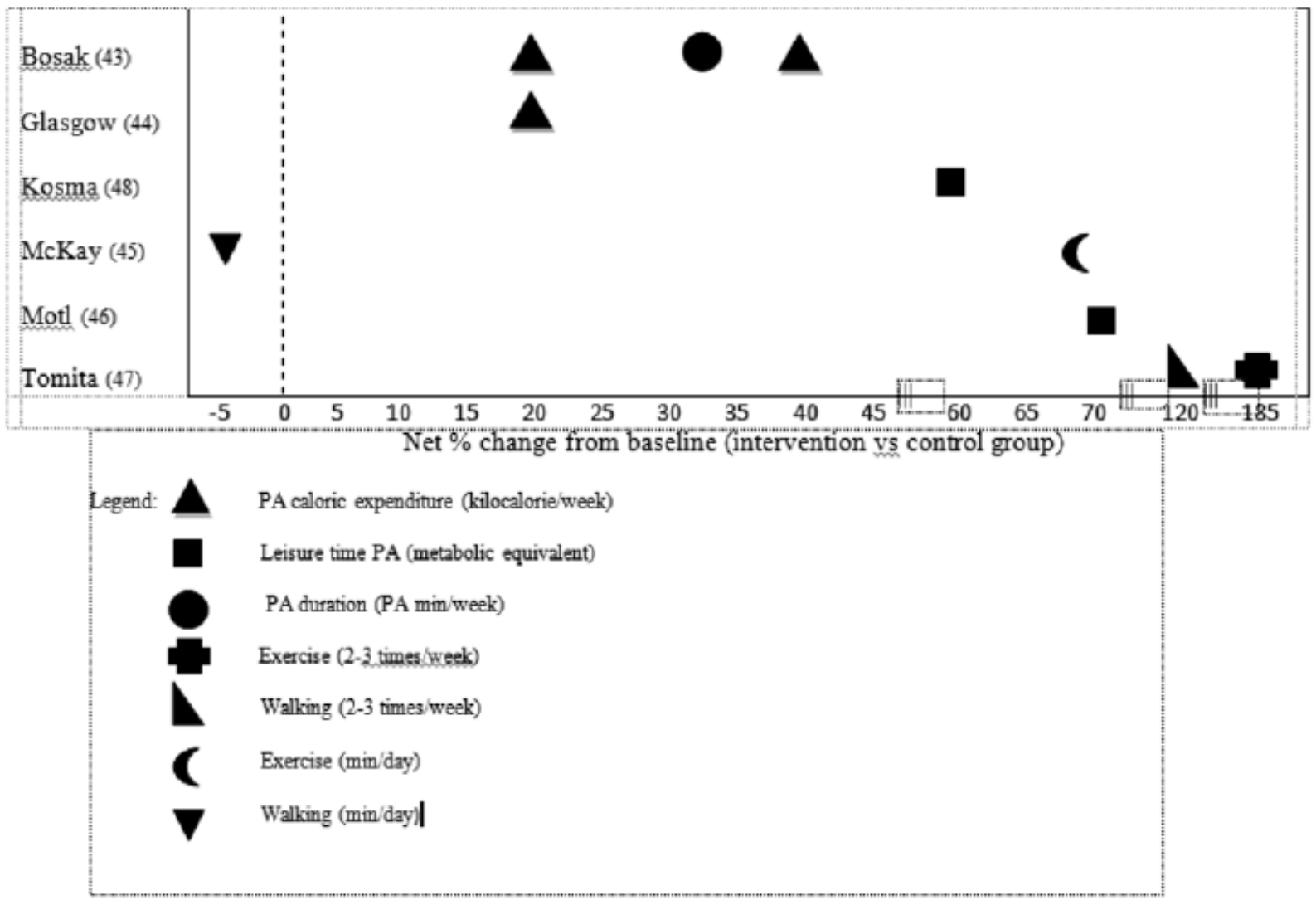

Figure 2 - Net percentage change in physical activity. 